\title{
Bloating and Abdominal Distension: Clinical Approach and Management
}

\author{
Amir Mari · Fadi Abu Backer · Mahmud Mahamid · Hana Amara • \\ Dan Carter · Doron Boltin · Ram Dickman
}

Received: February 5, 2019 / Published online: March 16, 2019

(C) The Author(s) 2019

\section{ABSTRACT}

Functional abdominal bloating and distension (FABD) are common gastrointestinal complaints, encountered on a daily basis by gastroenterologists and healthcare providers. Functional abdominal bloating is a subjective sensation that is commonly associated with an objective abdominal distension. FABD may be diagnosed as a single entity (the sole or cardinal

Enhanced Digital Features To view enhanced digital features for this article go to https://doi.org/10.6084/ m9.figshare.7776143.

A. Mari · F. Abu Backer

Gastroenterology Institute, Hillel Yaffe Medical

Center, Hadera, Israel

A. Mari · M. Mahamid · H. Amara

Gastroenterology Institute, Nazareth EMMS

Hospital, Nazareth, Israel

A. Mari · M. Mahamid

Faculty of Medicine in the Galilee, Bar-Ilan

University, Ramat Gan, Israel

D. Carter

Department of Gastroenterology, Chaim Sheba

Medical Center, Tel Hashomer, Ramat Gan, Israel

D. Boltin · R. Dickman ( $₫)$

Division of Gastroenterology, Rabin Medical Center, Beilinson Hospital, Petah Tikva, Israel

e-mail: dickmanr1@gmail.com

D. Carter · D. Boltin · R. Dickman

Sackler Faculty of Medicine, Tel Aviv University,

Tel Aviv, Israel complaint) or may overlap with other functional gastrointestinal disorders such as functional constipation, irritable bowel syndrome, and functional dyspepsia. The pathophysiology of FABD is not completely understood. Proposed underlying mechanisms include visceral hypersensitivity, behavioral induced abnormal abdominal wall-phrenic reflexes, the effect of poorly absorbed fermentable carbohydrates, and microbiome alterations. Management includes behavioral therapy, dietary interventions, microbiome modulation, and medical therapy. This review presents the current knowledge on the pathophysiology, evaluation, and management of FABD.

Keywords: Distension; Functional abdominal bloating; Functional constipation; Functional dyspepsia; Irritable bowel syndrome

\section{DEFINITION}

In 2016, the Rome IV working team revised the Rome III diagnostic criteria and updated the clinical evaluation and treatment for functional abdominal bloating and distension (FABD) [1]. According to the Rome IV, FABD is characterized by (subjective) symptoms of recurrent abdominal fullness, pressure, or a sensation of trapped gas (bloating), and/or measurable (objective) increase in abdominal girth (distention) 
Table 1 Non-functional etiologies for abdominal bloating and distension

Celiac disease

Lactose, fructose, and other carbohydrates intolerance

Pancreatic insufficiency

Gastroparesis

Diabetes mellitus

Hypothyroidism

Scleroderma

Chronic idiopathic pseudo-obstruction

Small bowel bacterial overgrowth

Acute gastroenteritis

Gastric malignancy

Bowel malignancy

Ovarian malignancy

Ascites

[1]. Bloating and distension may be the manifestations of organic disorders which should be diagnosed and treated separately. Common non-functional etiologies are listed in (Table 1).

Primary FABD should be diagnosed as a single entity (the sole or cardinal complaint) that does not overlap with other functional gastrointestinal disorders (FGID) such as functional constipation (FC), irritable bowel syndrome (IBS), and functional dyspepsia (FD). However, Rome IV diagnostic criteria permit the coexistence of mild abdominal pain and/or minor bowel movement abnormalities. Finally, symptom onset should be at least 6 months before diagnosis and the predominant symptom (bloating or distention) should be present during the last 3 months [1].

\section{EPIDEMIOLOGY}

Bloating and distension have been reported by $30 \%$ of the adult general population and are almost universal among patients with IBS [2]. However only about half of the patients with bloating also report abdominal distension. In addition, bloating is more common among patients with IBS, and distension is more common in patients with chronic constipation [3]. A telephone survey reported a prevalence of $16 \%$ in US adults who were asked about bloating or distension during the last month [4]. Women were more likely than men to report bloating (19\% vs $10.5 \%$ ) and were more likely to have severe symptoms (24\% vs $13 \%$ ). However, other studies have not identified different prevalence rates of bloating by gender $(21 \%$ and 19\%) $[3,5]$.

\section{PATHOPHYSIOLOGY}

The pathophysiology of FABD is multifactorial and not completely understood. Several underlying mechanisms have been proposed and may coexist in an individual patient (Fig. 1).

\section{Increased Intraluminal Content}

Intraluminal content includes gas, air, water, and fecal material. Air and gas may become abundant within the lumen through aerophagia and potentially from overproduction of gas by colonic or small intestine bacteria [6]. Small intestinal bacterial overgrowth (SIBO), gas underabsorption, and diet high in fermentable, poorly digested and absorbed carbohydrates may all play a role [7]. However, recent studies have shown minimal, if any, differences in gas contents between IBS and healthy controls who consumed similar amounts of fermentable carbohydrates [8, 9]. In another study comparing gas contents using a novel abdominal CT method, Accarino et al. did not find any change in the total abdominal volume during episodes of severe bloating, compared to baseline [10]. Therefore, on the basis of the mentioned studies, excessive intraluminal gas is unlikely to be a major underlying mechanism for symptom generation in FABD. 


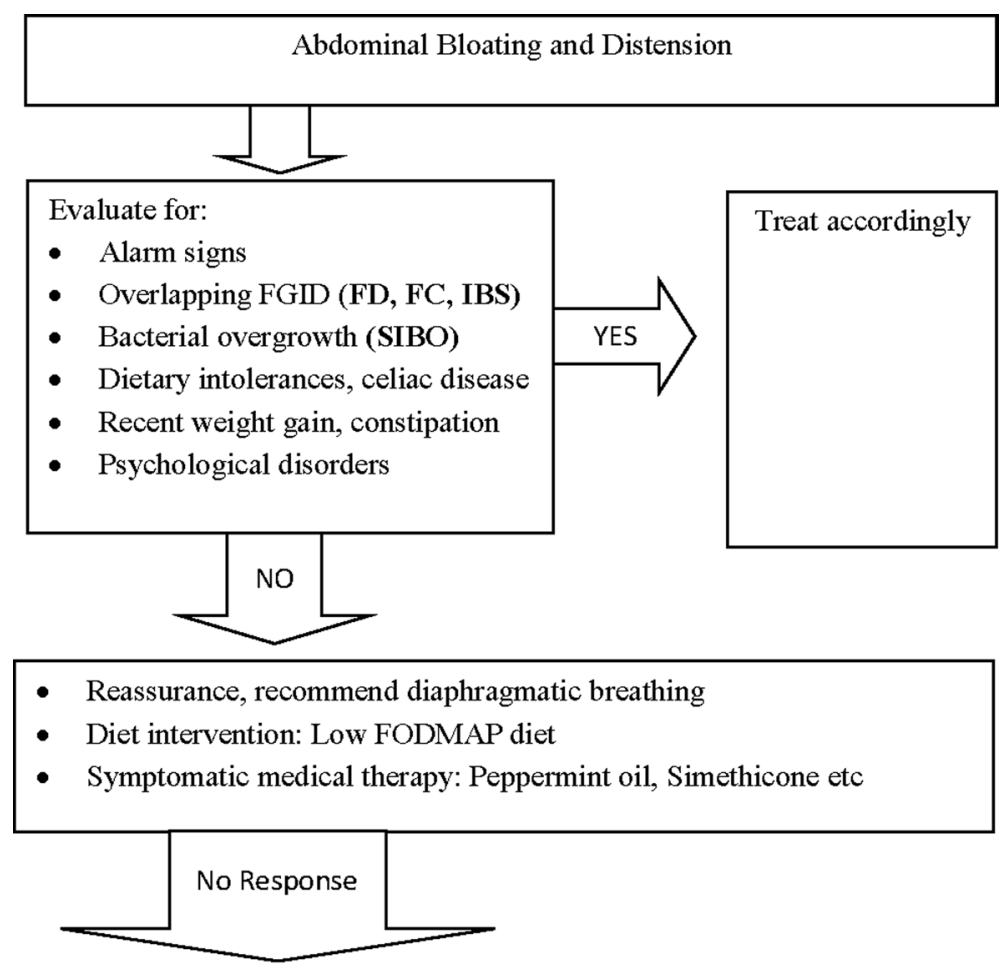

- Trial of Rifaximin/probiotics

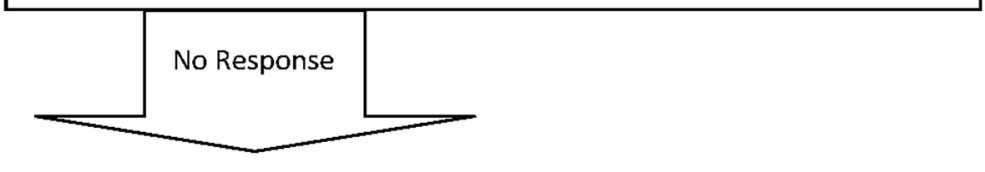

- Antidepressants

- Psychological therapy

- Hypnotherapy, cognitive behavioral therapy (CBT)

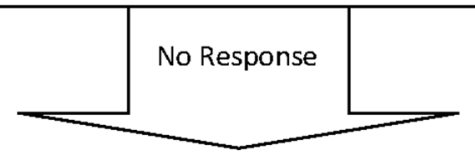

- Refer to a Neurogastroenterology Center

- Refer to CT or MRI Electromyography

- Refer to abdominal biofeedback therapy

Fig. 1 Algorithm for the approach and management of abdominal bloating and distension. FGID functional gastrointestinal disorders, $F C$ functional constipation,

\section{Visceral Hypersensitivity}

Functional abdominal bloating and distension may originate from increased gut sensitivity and abnormally increased attention to
IBS irritable bowel syndrome, $F C$ functional dyspepsia, $S I B O$ small intestinal bacterial overgrowth

intraluminal contents. In fact, patients with IBS have an increased awareness of their gut contents and motility, and may experience normal or slightly altered gut intraluminal content as bloating [11]. In their comprehensive review, 
Malagelada et al. used the term "conscious perception" to explain the role of the brain-gut axis in symptom generation (abdominal bloating). According to this model, visceral allodynia (seen also in IBS) is responsible for the bloating sensation that occurs in the presence of normal or only mildly increased amounts of intraluminal gas or other bowel content [12].

\section{Abdomino-Phrenic Dyssynergia}

This term, coined by the Barcelona group, describes the response of patients with FABD to a meal. According to studies by the group, patients with FABD have an abnormal muscle activity characterized by anterior abdominal wall relaxation and diaphragm contraction. This activity redistributes abdominal gas, thereby causing an anterior wall protrusion and visible distension. This is in contrast to healthy controls who in response to a meal experience contraction of anterior abdominal wall muscles and relaxation of the diaphragm [10]. The reason for this paradoxical maneuver in FABD is not completely understood. It may be related to an abnormal viscero-somatic response to innocuous intraluminal stimuli involving the brain-gut axis. Regardless of its cause, the description of abdomino-phrenic dyssynergia represents a novel and major mechanism that may explain the occurrence of FABD [12].

\section{Constipation and Outflow Obstruction}

Functional abdominal bloating and distension may be related to constipation and to functional outflow obstruction. Retained stool in the rectum may cause impaired gas evacuation and slowing of intestinal transit [13]. Compared with healthy volunteers, patients with FABD have a slower colonic transit [14]. Randomized controlled trails show that patients with constipation-predominant IBS (IBS-C) treated with lubiprostone or linaclotide experience a significant improvement in bloating [15-17]. Furthermore, among patients with functional outlet obstruction (dyssynergia), prolonged balloon expulsion correlates with the presence of FABD [18].

\section{Obesity}

Rapid weight gain and weight loss are associated with aggravation and improvement in bloating, respectively [12]. In one study, recent weight gain coincided with new onset bloating in 25\% of the participants [5]. A possible mechanism may involve an abnormal viscero-somatic reflex originating in the abdominal adipose tissue which modulates the brain-gut axis, resulting in FABD $[12,19]$.

\section{Dysbiosis}

Aberrant constitution or alteration in colonic microbacteria may lead to increased production of colonic gas by fermentation or decreased gas consumption, leading to increased colonic gas content and bloating [20]. Collins et al. found that interruption of the host-microbiota equilibrium affects the intestinal immune system and leads to inflammation. This, in turn, leads to gut sensory and motor dysfunction which may contribute to bloating [21]. Others have noted a relationship between colonic flora and the chemical composition of colonic gas. An interesting finding is that low producers of methane describe increased bloating following ingestion of sorbitol and fiber [22]. Molecular analysis of fecal samples from IBS patients have failed to demonstrate a clear unifying texture for the IBS microbiome, but have revealed an increased ratio of Firmicutes to Bacteroidetes species [23]. More recently, Ringel-Kulka et al. investigated the relationship between the intestinal microbiota, abdominal bloating, and altered bowel patterns in a cohort of patients with IBS and found significant changes in microbiota among different IBS subtypes. In particular, the authors noted that bloating was associated with specific microbial taxa [24].

\section{Psychological Comorbidities}

The relationship between psychological comorbidities and FABD has not been fully investigated. Nevertheless, it has been suggested that stress may contribute to increased perception of abdominal bloating. In one study it was 
reported that women with bloating frequently reported a history of depression and anxiety [25].

\section{EVALUATION}

As for any other medical condition, evaluation starts with a detailed medical history, physical examination, and appropriate diagnostic tests. As mentioned, it is crucial to exclude any organic cause for bloating and distention, including celiac disease or any other malabsorptive disorder, gut dysmotility, and chronic intestinal pseudo-obstruction. Common organic etiologies responsible for abdominal bloating and distension are described in Table 1.

In addition, the presence of alarm signs, such as weight loss, rectal bleeding, or anemia, should be investigated immediately. History taking should focus on diurnal changes, relationship to certain foods or food components (dairy products, wheat, fructans, fat, fiber, poorly digested and absorbed carbohydrates), and change in bowel habits. The severity of FABD is often lowest in the morning/night and greatest post-prandial (after breakfast) and during the early evening [26]. Symptoms suggestive of an overlap with IBS, functional dyspepsia, or functional constipation should be recorded as well. A concurrent diagnosis of another FGID often changes treatment modalities.

A physical exam may reveal an increase in abdominal girth and signs of bowel obstruction. Rectal and pelvic examination should be performed in constipated patients. Abdominal distention may be objectively assessed by abdominal inductance plethysmography, an ambulatory device that can continuously measure patients' abdominal girth [27]. Although there are no validated guidelines for the evaluation of FABD, the Rome IV 2016 working group recommends basic diagnostic tests such as complete blood count (CBC) if anemia is suspected, celiac serology (and if positive, duodenal biopsies should be added), abdominal x-ray to rule out obstruction, and a breath test for the diagnosis of SIBO [28].

\section{TREATMENT}

After the exclusion of alarm signs, organic disease, and overlap with other FGID, the next step is to offer a stepwise, individualized treatment as described in Fig. 1. Patients with mild functional bloating may need merely reassurance that the condition is benign and does not herald any life-threatening disease.

\section{Symptomatic Treatment}

Several agents are available for the treatment of FABD. Antispasmodics have shown some clinical benefit in symptoms relief in some patients [12]. Simethicone was found to reduce the frequency and severity of gas, distention, and bloating in a double-blind trial [29]. In two other controlled trials, peppermint oil significantly reduced distention compared to placebo $[30,31]$. Despite their popularity, evidence is lacking in regard to other commonly used agents such as activated charcoal, Iberogast, and magnesium salts.

\section{Dietary Intervention}

The role of dietary therapy in the management of bloating symptoms is crucial and generally introduced early in the treatment plan. The main rationale of dietary therapy is to identify foods to which the patient is intolerant and thereby reduce excessive fermentation of food residues. Empiric restriction of lactose and other poorly absorbed carbohydrates may be initially performed [12]. Alternatively, a low FODMAP (fermentable oligosaccharides, disaccharides, monosaccharides, and polyols) diet and other elimination diets may be offered to patients with FABD who have failed restriction diets [32]. In our opinion, diet interventions with restrictive diets should be delivered by trained dieticians who closely collaborate with the clinician. This approach may increase the patient's compliance and reduce the risk of nutritional deficiencies. It should be noted that an over-restrictive diet may in and of itself alter the colonic microbiota with undesired consequences [33]. Although unproven, in certain 
cases it seems appropriate to assess objectively the presence of carbohydrate intolerances by performing the corresponding breath tests [12].

\section{Relief of Constipation}

Patients with chronic idiopathic constipation (CIC) and IBS-C commonly report of bloating. Lubiprostone, a chloride channel agonist, was found to decrease bloating in two placebo-controlled clinical trials that enrolled patients with IBS-C $[16,34]$. Prucalopride, a selective $5-\mathrm{HT}_{4}$ receptor agonist, was found to increase spontaneous bowel movements and to reduce bloating [35]. Similarly, linaclotide, a guanylate cyclase $\mathrm{C}$ agonist, was found to improve constipation (increased spontaneous bowel movements) and to reduce abdominal pain and bloating in patients with CIC and IBS-C [36-42].

Finally, in one small placebo-controlled clinical trial, intravenous administration of neostigmine was found to enhance clearance of infused jejunal gas in a cohort of patients with abdominal bloating [43]. However, in another trial of IBS patients with bloating, it was found that pyridostigmine provided only a minimal effect on symptoms [44].

\section{Microbiome Modulation}

Reducing gas-producing bacteria or causing alterations of their metabolic activities may decrease excessive fermentation and bloating. Rifaximin, a poorly absorbed broad-spectrum antibiotic, was found to improve bloating and flatulence in controlled trials in patients with and without IBS $[45,46]$. Probiotics may become a therapeutic option in FABD; however, studies have revealed mixed results, probably due to the lack of standardized study methods $[47,48]$. In a recent review, it was suggested that probiotics have a role in the treatment of functional gastrointestinal disorders [49]. In a double-blind study by Ringel et al. it was shown that Lactobacillus acidophilus and Bifidobacterium lactis Bi-07 improved bloating in non-constipated patients with FGID [50].

\section{Abdominal Biofeedback Therapy}

As previously described, post-prandial FABD may result from abnormal anterior abdominal wall relaxation and diaphragmatic contraction. These behaviors cause a redistribution of intrabdominal gas, resulting in an anterior wall protrusion and visible distension [10].

The explanation for these behaviors may be related to an abnormal viscero-somatic reflex, causing a thoraco-abdominal striated muscular activity that reshapes the abdomen and pushes it to protrude anteriorly [12]. This abnormal reflex activity or behavior is potentially amenable to biofeedback therapy. In fact, Barba et al. showed that it is possible to educate patients on how to use their abdominal and diaphragmatic muscles [51]. FGID patients with distension were randomized to biofeedback or placebo. Biofeedback sessions were offered on separate days up to three times during a 1- to 2-week period $[12,51]$. Biofeedback effectively diminished diaphragmatic and intercostal muscle contraction, decreasing both subjective bloating and abdominal girth [51]. These findings suggest that FABD may be improved by performing diaphragmatic or abdominal breathing. This simplification of biofeedback training, $5 \mathrm{~min}$ before and $5 \mathrm{~min}$ after meals, effectively relaxes the intercostal muscles and the diaphragm while contracting the anterior abdominal muscles [51].

\section{Modulating the Brain-Gut Axis}

If an amplified perception of bowel wall stretch and visceral hypersensitivity are key components in the pathogenesis of FABD, then modulating the brain-gut axis seems to be a reasonable treatment option. Antidepressants, such as tricyclic antidepressant (TCA) and selective serotonin reuptake inhibitors (SSRIs) and selective noradrenalin reuptake inhibitors (SNRI), were evaluated in patients with IBS. However, their exact role of these antidepressants in improving bloating symptoms is unclear $[52,53]$. In a small, controlled crossover study, citalopram (an SSRI) showed an increase 
in the number of days without bloating at 3 and 6 weeks [53].

In another study, desipramine (TCA) combined with cognitive behavioral therapy decreased bloating [54]. Hypnotherapy and cognitive behavioral therapy, which are commonly offered to patients with IBS, may also be effective in patients with FABD $[12,55]$.

\section{Compliance with Ethics Guidelines}

This review article is based on previously conducted studies and reviews and does not contain any studies with human participants or animals performed by any of the authors.

\section{SUMMARY}

Functional abdominal bloating and distension is a prevalent condition, with an adverse effect on general well-being and quality of life. Therapy may target gut motility, muscular tone, microbiota, visceral sensitivity, diet, and/or psychological comorbidity. A stepwise, multidisciplinary, individualized approach is desirable. Further studies are warranted to better elucidate the pathophysiological basis of FABD. Well-designed clinical trials in which bloating and distention are primary endpoints are needed to validate the putative treatments.

\section{ACKNOWLEDGEMENTS}

Funding. This research did not receive any specific grant from funding agencies in the public, commercial, or not-for-profit sectors. Additionally, no funding or sponsorship was received for the publication of this article.

Authorship. All named authors meet the International Committee of Medical Journal Editors (ICMJE) criteria for authorship for this article, take responsibility for the integrity of the work as a whole, and have given their approval for this version to be published.
Disclosures. The authors (Amir Mari, Fadi Abu Backer, Mahmud Mahamid, Hana Amara, Dan Carter, Doron Boltin and Ram Dickman) declare that they have no conflicts of interest.

Compliance with Ethics Guidelines. This review article is based on previously conducted studies and reviews and does not contain any studies with human participants or animals performed by any of the authors.

Data Availability. Data sharing is not applicable to this article as no datasets were generated or analyzed during the current study.

Open Access. This article is distributed under the terms of the Creative Commons Attribution-NonCommercial 4.0 International License (http://creativecommons.org/licenses/ by-nc/4.0/), which permits any noncommercial use, distribution, and reproduction in any medium, provided you give appropriate credit to the original author(s) and the source, provide a link to the Creative Commons license, and indicate if changes were made.

\section{REFERENCES}

1. Lacy B, Mearin F, Chang L, et al. Bowel disorders. Gastroenterology. 2016;150(6):1393-407.

2. Azpiroz F. Intestinal gas. In: Feldman M, Friedman LS, Brand LJ, editors. Pathophysiology, diagnosis, management. Philadelphia: Elsevier; 2015. p. 242-50.

3. Tuteja A, Talley N, Joos S, Tolman K, Hickam D. Abdominal bloating in employed adults: prevalence, risk factors, and association with other bowel disorders. Am J Gastroenterol. 2008;103(5):1241-8.

4. Sandler RS, Stewart WF, Liberman JN, Ricci JA, Zorich NL. Abdominal pain, bloating, and diarrhea in the United States: prevalence and impact. Dig Dis Sci. 2000;45(6):1166-71.

5. Jiang X, Locke G, Choung R, Zinsmeister A, Schleck $\mathrm{C}$, Talley N. Prevalence and risk factors for abdominal bloating and visible distention: a populationbased study. Gut. 2008;57(6):756-63. 
6. Drossman D. Functional gastrointestinal disorders: history, pathophysiology, clinical features, and Rome IV. Gastroenterology. 2016;150(6):1262-79.

7. Chang L, Lee O, Naliboff B, Schmulson M, Mayer E. Sensation of bloating and visible abdominal distension in patients with irritable bowel syndrome. Am J Gastroenterol. 2001;96(12):3341-7.

8. Azpiroz F, Malagelada J. Abdominal bloating. Gastroenterology. 2005;129(3):1060-78.

9. Fernández-Bañares F, Esteve-Pardo M, de Leon R, et al. Sugar malabsorption in functional bowel disease: clinical implications. Am J Gastroenterol. 1993;88:2044-205.

10. Accarino A, Perez F, Azpiroz F, Quiroga S, Malagelada J. Abdominal distention results from caudoventral redistribution of contents. Gastroenterology. 2009;136(5):1544-51.

11. Serra J, Azpiroz F, Malagelada J. Modulation of gut perception in humans by spatial summation phenomena. J Physiol. 1998;506(2):579-87.

12. Malagelada J, Accarino A, Azpiroz F. Bloating and abdominal distension: old misconceptions and current knowledge. Am J Gastroenterol. 2017;112(8):1221-31.

13. Houghton L, Lea R, Agrawal A, Reilly B, Whorwell P. Relationship of abdominal bloating to distention in irritable bowel syndrome and effect of bowel habit. Gastroenterology. 2006;131(4):1003-10.

14. Agrawal A, Houghton L, Reilly B, Morris J, Whorwell P. Bloating and distension in irritable bowel syndrome: the role of gastrointestinal transit. Am J Gastroenterol. 2009;104(8):1998-2004.

15. Drossman D, Chey W, Johanson J, et al. Clinical trial: lubiprostone in patients with constipationassociated irritable bowel syndrome-results of two randomized, placebo-controlled studies. Aliment Pharmacol Ther. 2009;29(3):329-41.

16. Chey W, Drossman D, Johanson J, Scott C, Panas R, Ueno R. Safety and patient outcomes with lubiprostone for up to 52 weeks in patients with irritable bowel syndrome with constipation. Aliment Pharmacol Ther. 2012;35(5):587-99.

17. Quigley E, Tack J, Chey W, et al. Randomised clinical trials: linaclotide phase 3 studies in IBS-C-a prespecified further analysis based on European Medicines Agency-specified endpoints. Aliment Pharmacol Ther. 2012;37(1):49-61.

18. Shim L, Prott G, Hansen R, Simmons L, Kellow J, Malcolm A. Prolonged balloon expulsion is predictive of abdominal distension in bloating. Am J Gastroenterol. 2010;105(4):883-7.

19. Accarino A, Azpiroz F, Malagelada J. Attention and distraction: effects on gut perception. Gastroenterology. 1997;113(2):415-22.

20. Simrén $\mathrm{M}$, Barbara $\mathrm{G}$, Flint $\mathrm{H}$, et al. Intestinal microbiota in functional bowel disorders: a Rome Foundation report. Gut. 2012;62(1):159-76.

21. Collins S, Denou E, Verdu E, Bercik P. The putative role of the intestinal microbiota in the irritable bowel syndrome. Dig Liver Dis. 2009;41(12): 850-3.

22. Vernia P, Camillo M, Marinaro V, Caprilli R. Effect of predominant methanogenic flora on the outcome of lactose breath test in irritable bowel syndrome patients. Eur J Clin Nutr. 2003;57(9): 1116-9.

23. Bennet SMP, Ohman L, Simren M. Gut microbiota as potential orchestrators of irritable bowel syndrome. Gut Liver. 2015;9(3):318-31.

24. Ringel-Kulka T, Benson A, Carroll I, Kim J, Legge R, Ringel Y. Molecular characterization of the intestinal microbiota in patients with and without abdominal bloating. Am J Physiol Gastrointest Liver Physiol. 2016;310(6):G417-26.

25. Barba E, Quiroga S, Accarino A, et al. Mechanisms of abdominal distension in severe intestinal dysmotility: abdomino-thoracic response to gut retention. Neurogastroenterol Motil. 2013;25(6): e389-94.

26. Maxton DG, Whorwell PJ. Abdominal distension in irritable bowel syndrome: the patient's perception. Eur Hepatol. 1992;4:241-3.

27. Lewis M. Ambulatory abdominal inductance plethysmography: towards objective assessment of abdominal distension in irritable bowel syndrome. Gut. 2001;48(2):216-20.

28. Dukowicz AC, Lacy BE, Levine GM. Small intestinal bacterial overgrowth: a comprehensive review. Gastroenterol Hepatol. 2007;3:112-22.

29. Bernstein J, Kasich A. A double-blind trial of simethicone in functional disease of the upper gastrointestinal tract. J Clin Pharmacol. 1974;14(11): 617-23.

30. Liu J, Chen G, Yeh H, Huang C, Poon S. Entericcoated peppermint-oil capsules in the treatment of irritable bowel syndrome: a prospective, randomized trial. J Gastroenterol. 1997;32(6):765-8. 
31. Cappello G, Spezzaferro M, Grossi L, Manzoli L, Marzio L. Peppermint oil (Mintoil ${ }^{\circledR}$ ) in the treatment of irritable bowel syndrome: a prospective double blind placebo-controlled randomized trial. Dig Liver Dis. 2007;39(6):530-6.

32. Halmos E, Power V, Shepherd S, Gibson P, Muir J. A diet low in FODMAPs reduces symptoms of irritable bowel syndrome. Gastroenterology. 2014;146(1): 67-75.

33. Catassi G, Lionetti E, Gatti S, Catassi C. The low FODMAP diet: many question marks for a catchy acronym. Nutrients. 2017;9(3):292.

34. Camilleri M, Bharucha A, Ueno R, et al. Effect of a selective chloride channel activator, lubiprostone, on gastrointestinal transit, gastric sensory, and motor functions in healthy volunteers. Am J Physiol Gastrointest Liver Physiol. 2006;290(5):G942-7.

35. Tack J, Stanghellini V, Dubois D, Joseph A, Vandeplassche L, Kerstens R. Effect of prucalopride on symptoms of chronic constipation. Neurogastroenterol Motil. 2013;26(1):21-7.

36. Castro J, Harrington A, Hughes P, et al. Linaclotide inhibits colonic nociceptors and relieves abdominal pain via guanylate cyclase-C and extracellular cyclic guanosine 3',5'-monophosphate. Gastroenterology. 2013;145(6):1334-1346.e11.

37. Limbo AJ, Schneier HA, Shiff SJ, et al. Two randomized trials of linaclotide for chronic constipation. N Engl J Med. 2011;365:527-36.

38. Rao S, Lembo AJ, Shiff SJ, et al. A 12-week, randomized, controlled trial with a 4-week randomized withdrawal period to evaluate the efficacy and safety of linaclotide in irritable bowel syndrome with constipation. Am J Gastroenterol. 2012;107: 1714-24.

39. Chey WD, Lembo AJ, Lavins BJ, et al. Linaclotide for irritable bowel syndrome with constipation: a 26-week, randomized, double-blind, placebo-controlled trial to evaluate efficacy and safety. Am J Gastroenterol. 2012;107:1702-12.

40. Quigley EMM, Tack J, Chey WD, et al. Randomised clinical trials: linaclotide phase 3 studies in IBS-Ca prespecified further analysis based on European Medicines Agency-specified endpoints. Aliment Pharmacol Ther. 2013;37:49-61.

41. Lacy BE, Schey R, Shiff SJ, et al. Linaclotide in chronic idiopathic constipation patients with moderate to severe abdominal bloating: a randomized, controlled trial. PLoS One. 2015;10:e0134349.

42. Videlock E, Cheng V, Cremonini F. Effects of linaclotide in patients with irritable bowel syndrome with constipation or chronic constipation: a metaanalysis. Clin Gastroenterol Hepatol. 2013;11(9): 1084-1092.e3.

43. Caldarella M, Serra J, Azpiroz F, Malagelada J. Prokinetic effects in patients with intestinal gas retention. Gastroenterology. 2002;122(7):1748-55.

44. Accarino A, Perez F, Azpiroz F, Quiroga S, Malagelada J. Intestinal gas and bloating: effect of prokinetic stimulation. Am J Gastroenterol. 2008;103(8): 2036-42.

45. Pimentel M, Lembo A, Chey W, et al. Rifaximin therapy for patients with irritable bowel syndrome without constipation. N Engl J Med. 2011;364(1): 22-32.

46. Sharara A, Aoun E, Abdul-Baki H, Mounzer R, Sidani $\mathrm{S}$, ElHajj I. A randomized double-blind placebocontrolled trial of rifaximin in patients with abdominal bloating and flatulence. Am J Gastroenterol. 2006;101(2):326-33.

47. Moayyedi P, Ford A, Talley N, et al. The efficacy of probiotics in the treatment of irritable bowel syndrome: a systematic review. Gut. 2008;59(3): 325-32.

48. Jonkers D, Stockbrügger R. Review article: probiotics in gastrointestinal and liver diseases. Aliment Pharmacol Ther. 2007;26:133-48.

49. Ringel Y, Carroll I. Alterations in the intestinal microbiota and functional bowel symptoms. Gastrointest Endosc Clin N Am. 2009;19(1):141-50.

50. Ringel-Kulka T, Palsson O, Maier D, et al. Probiotic bacteria Lactobacillus acidophilus NCFM and Bifidobacterium lactis bi-07 versus placebo for the symptoms of bloating in patients with functional bowel disorders. J Clin Gastroenterol. 2011;45(6):518-25.

51. Barba E, Burri E, Accarino A, et al. Abdominothoracic mechanisms of functional abdominal distension and correction by biofeedback. Gastroenterology. 2015;148(4):732-9.

52. Tack J. A controlled crossover study of the selective serotonin reuptake inhibitor citalopram in irritable bowel syndrome. Gut. 2005;55(8):1095-103.

53. Rahimi R, Nikfar S, Abdollahi M. Efficacy and tolerability of Hypericum perforatum in major depressive disorder in comparison with selective serotonin reuptake inhibitors: a meta-analysis. Prog Neuropsychopharmacol Biol Psychiatry. 2009;33(1):118-27.

54. Drossman D, Toner B, Whitehead W, et al. Cognitive-behavioral therapy versus education and 
desipramine versus placebo for moderate to severe functional bowel disorders. Gastroenterology. 2003;125(1):19-31.
55. Schmulson M, Chang L. Review article: the treatment of functional abdominal bloating and distension. Aliment Pharmacol Ther. 2011;33(10):1071-86. 